\title{
IMPLICAÇÕES DE UMA PERSPECTIVA REALISTA DIRETA PARA O PAM-L2: DESAFIOS TEÓRICO-METODOLÓGICOS
}

\author{
Ubiratã Kickhöfel ALVES ${ }^{1}$ \\ Adelaide Hercília Pescatori SILVA ${ }^{2}$
}

Resumo: Neste trabalho, discutimos as premissas de base realista direta e ecológica do Perceptual Assimilation Model-L2 (PAM-L2) (BEST; TYLER, 2007), de modo a apontar os principais aspectos, bem como os desafios teórico-metodológicos, advindos da concepção adotada pelo modelo. A discussão será alicerçada a partir dos seguintes pontos de discussão: (i) a consonância entre a teoria de base do PAM-L2 e a realização de estudos laboratoriais; (ii) o poder explanatório do modelo frente à questão da transferência grafo-fônico-fonológica; (iii) a concepção ecológica e o debate "Segunda Língua" vs. "Língua Estrangeira"; (iv) a aplicação ou não do modelo frente a estudos de treinamento perceptual; (v) a noção ecológica frente ao binômio "percepção"-“inteligibilidade". Esperamos, com o presente trabalho, proporcionar um entendimento maior, por parte dos pesquisadores, acerca das teorias de base e da concepção de língua que regem o PAM-L2.

Palavras-chave: Percepção da fala; Aquisição de L2/LE; Abordagem Ecológica; Realismo Direto.

\section{Introdução}

Nos últimos anos, considerando-se o cenário de investigações brasileiras, verificamos um grande crescimento nos estudos voltados à área de aquisição fonético-fonológica de LE. Notável, também, é o aumento do número de trabalhos acerca do processo de percepção de sons da língua-alvo. Esse crescimento, em grande parte, deve-se a uma maior acessibilidade propiciada por softwares livres, dentre os quais se destacam o Praat $^{3}$ (BOERSMA;

\footnotetext{
1 Departamento de Línguas Modernas da Universidade Federal do Rio Grande do Sul (UFRGS). E-mail: ukalves@gmail.com

2 Departamento de Literatura e Linguística da Universidade Federal do Paraná (UFPR). E-mail: adelaidehpsilva@gmail.com

${ }^{3}$ O PRAAT pode ser baixado gratuitamente a partir do site: www.praat.org.
} 
WEENINK, 1992-presente data) e o $\mathrm{TP}^{4}$ (RAUBER et al., 2015-presente data). Esses programas, de fácil manuseio, permitem a elaboração de experimentos controlados com grande rigor metodológico. Em meio a esse novo quadro tecnológico, cada vez mais os estudos da área investem em metodologias elaboradas e questões de pesquisas instigantes que se voltam à percepção do componente fonético-fonológico e, também, à relação entre a percepção e a produção dos sistemas de sons de uma nova língua.

Dentre os modelos perceptuais adotados como base teórica para as investigações empíricas, tanto no cenário brasileiro quanto no mundial, dois deles mostram-se bastante em voga no quadro atual de estudos: o Speech Learning Model (FLEGE, 1995, 2003) e o Perceptual Assimilation Model-L2 (BEST; TYLER, 2007) 5 . Na maioria desses estudos, inclusive, ambos os modelos acabam sendo adotados conjuntamente, apesar das consideráveis divergências, em termos de teoria de base, que motivam cada uma das proposições.

No presente trabalho, voltamo-nos à discussão acerca do Perceptual Assimilation Model-L2 (PAM-L2). Tal modelo tem origem na proposta inicial de Best (1994a, 1994b, 1995), destinada à percepção de aprendizes ingênuos (do inglês, naive learners), ou seja, participantes que não possuem contato algum com o novo idioma que caracteriza o sistemaalvo. Desde a década de 1990, os postulados de Best, bem como as suas previsões de assimilação entre sons ${ }^{6}$, vêm sendo empregados para explicar os casos de aquisição de L2/LE, tanto em estudos nacionais e internacionais, ainda que tais casos não correspondessem ao foco do modelo proposto. Em 2007, em uma obra em homenagem a James Flege (MUNRO; BOHN, 2007), Best e Tyler, então, propõem uma versão do PAM adaptada aos pressupostos de aquisição de $\mathrm{L}^{7}$. No referido trabalho, os autores, além de discutirem semelhanças e diferenças entre a proposta do SLM e os postulados do modelo inicial da década de 90, visam

\footnotetext{
${ }^{4}$ O TP pode ser baixado gratuitamente a partir do site: http://www.worken.com.br/tp_regfree.php.

5 Ainda que esses sejam os modelos perceptuais prioritariamente adotados no quadro de estudos brasileiros, devemos mencionar a alusão a outros modelos, encontrada em trabalhos de pós-graduação desenvolvidos em nosso país. Vejam-se, por exemplo, os recentes trabalhos de Machry da Silva (2014), cuja revisão teórica também faz menção à proposta de Strange (2011), e o de Santos (2014), que estabelece considerações acerca do modelo de Escudero; Boersma (2002).

${ }^{6}$ Para fins de delimitação, optamos por não resenhar a proposta e os postulados originais de Best (1995) e Best e Tyler (2007). Assumimos, pois, que o leitor já se encontra familiarizado com os textos originais supracitados, cujas leituras se mostram fundamentais para o entendimento das discussões realizadas ao longo deste artigo. Para boas resenhas, em língua portuguesa, desses trabalhos fundadores, aconselhamos as leituras de Bettoni-Techio (2008), Reis (2011), Albuquerque (2012) e Perozzo (2013).

${ }^{7}$ Conforme será visto no que segue, Best e Tyler (2007) fazem uma distinção entre os contextos de Segunda Língua (L2) e Língua Estrangeira (LE). Apesar de tal distinção, vários são os trabalhos de pós-graduação, em nosso país, que fazem uso desse modelo, considerando-se um contexto brasileiro de aquisição de língua estrangeira (cf. BETTONI-TECHIO, 2008; ALBUQUERQUE, 2012; PEROZZO, 2013; SCHWARTZHAUPT, 2015, dentre outros). Uma discussão a respeito da pertinência desse emprego será apresentada em breve neste texto.
} 
à elaboração de uma nova proposta, que vá além daquelas previsões estabelecidas para aprendizes ingênuos ${ }^{8}$.

Ainda que seja considerada a intenção de Best e Tyler (2007) de oferecer aos pesquisadores um modelo que, de certa forma, apresente uma série de coincidências com aquele proposto por Flege, os autores deixam claro, desde o trabalho inicial, que as teorias de base que sustentam o PAM-L2 se mostram distintas daquelas do SLM. Seguindo a mesma linha teórico-metodológica adotada na proposta voltada a aprendizes ingênuos, o PAM-L2 é, também, alicerçado sobre a perspectiva perceptual do Realismo Direto, a partir de uma abordagem ecológica de percepção (GIBSON, 1966, 1979), de modo a, na mesma linha traçada por Fowler $(1986,1996)$, considerar como unidade linguística o gesto articulatório (BROWMAN; GOLDSTEIN, 1986, 1992).

Uma vez que as propostas de predições de assimilação preconizadas por Best (1995) e Best e Tyler (2007) mostram um caráter elegante, de fácil acesso e entendimento para os pesquisadores, a discussão sobre as bases teóricas e as consequências teórico-metodológicas advindas da adoção desse modelo passam a ser, muitas vezes, relegadas a um segundo plano nas análises de dados dos estudos que empregam esse modelo. $\mathrm{O}$ presente artigo tem, justamente, o objetivo de discutir a abordagem "ecológica", de cunho realista direto, adotada no trabalho de Best e Tyler (2007), o que permitirá uma reflexão sobre os desafios teóricometodológicos a serem enfrentados no que diz respeito à aplicação do PAM-L2. Ao discutirmos os modelos fundadores da proposta, esperamos promover uma reflexão acerca das questões teóricas, bem como metodológicas, que ainda carecem de maior atenção para o contínuo desenvolvimento da proposta. Mais do que isso, esperamos, sobretudo, que o presente trabalho contribua para que a adoção do PAM-L2, por parte dos pesquisadores da área, constitua uma escolha consciente e embasada nos preceitos teóricos sobre os quais se alicerça tal modelo.

Dado o objetivo acima proposto, o artigo será organizado da seguinte forma: primeiramente, discutiremos as teorias de base que sustentam o modelo, de modo a promover uma reflexão sobre como a proposta concilia uma teoria psicológica de percepção, como o realismo direto, à unidade do gesto articulatório enquanto primitivo fonológico. Em um segundo momento do texto, apresentaremos questionamentos e desafios a serem, ainda, enfrentados pelos usuários do modelo, a partir de investigações futuras a respeito das suas

\footnotetext{
8 Por fins de delimitação, não é tampouco nosso objetivo, aqui, discutir diferenças epistemológicas e metodológicas entre as propostas de Best (1995) e Best e Tyler (2007). Ainda assim, é preciso dizer que ambos os modelos apresentam diferenças consideráveis, conforme a leitura dos referidos artigos pode apontar.
} 
questões de base. Discutiremos, sobretudo, os desafios advindos da noção ecológica de percepção. Ao encerrarmos o artigo, promoveremos uma breve retomada das questões levantadas, chamando a atenção do leitor para a necessidade de estudos futuros que invistam em uma metodologia experimental que, ao mesmo tempo em que consiga testar adequadamente as previsões teóricas do PAM-L2, esteja coerente com os pressupostos basilares da proposta.

\section{Bases teóricas do PAM-L2}

Ao iniciarmos nossa discussão acerca das bases teóricas que motivam o PAM-L2, pretendemos expressar como concebemos uma possível resposta para a seguinte questão: o que significa perceber os elementos fônicos, considerando-se as unidades de base expressas pelo Perceptual Assimilation Model-L2? Ao considerarmos que a proposta de 2007 prevê a formação de novas categorias fonológicas com base na exposição do aprendiz ao input, cabenos, também, questionar como se dá o processo de aprendizado da percepção (cf. GIBSON; GIBSON, 1955), levando-se em conta os primitivos que serviram de base para o modelo. Essas respostas ${ }^{9}$, a serem discutidas ao final desta seção, servirão também como um fio condutor que permitirá analisar os desafios teórico-metodológicos ainda a serem enfrentados pelo modelo.

\section{Sobre as teorias de percepção da fala}

O debate acerca de como percebemos o que está ao nosso redor, através de diferentes órgãos de sentido, ainda se mostra inconclusivo. Diversas são as propostas, divergentes entre si, que tentam explicar como percebemos o mundo. Conforme nos explica Gordon (2004), ao se referir a modelos de percepção visual, as teorias vigentes ainda carecem do rigor que caracteriza as grandes teorias científicas, visto que tampouco há um consenso acerca do que precisa ser explicado no que respeita à percepção - se a experiência consciente, se mecanismos neurobiológicos, se as características do ambiente em que estamos inseridos, ou se, ainda, outros aspectos. Nesse sentido, a busca por uma teoria geral de percepção, que

\footnotetext{
${ }^{9}$ Cabe esclarecer, ainda, que as referidas respostas são fruto de nossa própria interpretação acerca do emprego das bases teóricas utilizadas por Best (1995) e Best e Tyler (2007). Dessa forma, mais do que responder ao que significa "o que é perceber" de acordo com o que concebem os autores do modelo, é importante expressar que estamos aqui discutindo como consideramos que pode ser pensada a percepção fônica dentro da referida proposta, a partir de tais bases teóricas. Possíveis diferenças entre a leitura aqui apresentada e as concepções iniciais, expressas por Best e Tyler (2007), são dignas de futuras discussões pelos pesquisadores da área.
} 
corresponda a um consenso entre pesquisadores, mostra-se, ainda, como um objetivo inatingível (op. cit., p. 218). Em meio a diferentes perspectivas, temos desde modelos de percepção de caráter mais mentalista, até propostas que se voltam completamente à natureza do input considerado rico, de modo que permaneçam as dúvidas acerca de "até que ponto a percepção é determinada por estimulação (de modo a envolver processos do tipo bottom-up) ou por conhecimento prévio (processos top-down)" (op. cit., p. 217).

A questão central que motiva os estudos perceptuais da fala, conforme explicam Diehl, Lotto e Holt (2004), diz respeito a como os ouvintes extraem os elementos linguísticos a partir do sinal acústico. Essa discussão, segundo Nishida (2014a), teve origem na década de 1950, nos laboratórios Haskins, quando se começou a questionar se, ao invés de ser realmente guiada pela audição do sinal acústico, a percepção seria guiada pela articulação. Tal questionamento tinha origem, justamente, nos achados, por parte dos pesquisadores do referido laboratório, de que o sinal acústico apresentava grande variação, não havendo uma correspondência de um-por-um entre a informação acústica e o segmento (observação essa motivada, sobretudo, pelos achados referentes às transições formânticas entre vogais e consoantes antecedentes e seguintes).

Dessa forma, no cenário de estudos perceptuais da fala, surgem, além da abordagem psicoacústica de percepção, outras duas visões baseadas no gesto como unidade primitiva: a Teoria Motora de Percepção da Fala (LIBERMAN et al., 1967; LIBERMAN; MATTINGLY, 1985) e a Teoria Realista Direta de Percepção da Fala (FOWLER, 1986, 1996) ${ }^{10}$. Ainda que esses dois modelos tenham, em tese, a mesma unidade de análise (o gesto articulatório), e que, por serem oriundos do mesmo centro de investigações, não constituam propostas que compitam diretamente entre si (cf. NISHIDA, op. cit.), é necessário destacar que a natureza do gesto expressa por cada modelo se mostra bastante diferente. Conforme explicam Diehl, Lotto e Holt (2004), a Teoria Motora concebia o gesto como comandos neuromotores de caráter abstrato, constituintes de um mecanismo especial de linguagem. Por sua vez, na abordagem realista, os gestos são concebidos como elementos "reais", encontrados no ambiente considerado rico.

\footnotetext{
${ }^{10}$ Para uma descrição de outros modelos perceptuais além dos três aqui referidos, aconselhamos a leitura de Tatham e Morton (2011).
} 


\section{O Realismo Direto como base para o Perceptual Assimilation Model}

Concentremo-nos, pois, na Teoria do Realismo Direto, que constitui a base perceptual para a proposta do Perceptual Assimilation Model ${ }^{11}$. A noção de realismo direto voltada à percepção da fala, iniciada sobretudo por Fowler $(1986,1996)^{12}$, teve por base a Abordagem Ecológica, de Gibson (1966, 1979), para a visão. De acordo com a proposta do autor, a referida abordagem recebe esse nome porque o ambiente é não somente a fonte de informações, mas é, também, parte do indivíduo. O ambiente existe porque existe um indivíduo e vice-versa. Nesse sentido, percebemos o mundo ao nosso redor, porém esse mundo, segundo as palavras do autor (GIBSON, 1979, p. 6), "não é o mundo da física, mas, sim, o mundo no nível da ecologia", com o qual o indivíduo interage. O termo "ambiente", portanto, é definido pelo autor (GIBSON, 1979, p. 7) como os "arredores daqueles organismos que percebem e se comportam, ou seja, os animais", de modo que as palavras "ambiente" e "animal" formem um par inseparável. É importante ressaltar que a noção de relação entre animal e ambiente, para Gibson, é uma relação de interação que implica percepção e comportamento, sendo esses últimos dois termos, também, difíceis de serem desassociados. Nesse sentido, todo o animal percebe as modificações e mudanças realizadas no ambiente ${ }^{13}$ ao mesmo tempo em que age nesse mesmo ambiente. É dispensada, assim, a fórmula "estímulo-resposta", e, também, um tratamento mentalista para a percepção.

Essa noção de interação mútua e de indissociabilidade é fundamental para o entendimento do conceito de "affordance"14, que constitui uma das bases da abordagem a ser empregada, posteriormente, em Best (1995) e Best e Tyler (2007). As affordances constituem propriedades dos objetos encontrados no ambiente, de modo que, segundo Gibson (1979, p. 127), "as affordances de um ambiente são o que esse ambiente oferece ao animal, o que ele provê e fornece, tanto para o bem quanto para o mal". As affordances, em outras palavras, constituem propriedades do ambiente que possibilitam, justamente, a interação desse

\footnotetext{
${ }^{11}$ Por motivos de delimitação, focalizaremos, sobretudo, a abordagem do Realismo Direto. Para uma descrição das premissas e das diferenças entre os três modelos perceptuais aqui referidos, aconselhamos a leitura de Diehl et al. (2004) e de Nishida (2012), este último em Língua Portuguesa. Para uma descrição das diferenças entre a Teoria Motora e do Realismo Direto, sugere-se a leitura de Nishida (2014a, 2014b).

12 Julgamos pertinente mencionar que, no artigo em que advogam a necessidade de uma moeda gestual comum para percepção e produção, Goldstein e Fowler (2003) mencionam, além dos estudos de Fowler supracitados, o trabalho de Best (1995) como um dos artigos fundadores da Teoria Direta de Percepção da Fala.

${ }^{13}$ Considerando-se essa afirmação, podemos atribuir à proposta de Gibson um caráter dinâmico, uma vez que o ambiente, para o autor, é resultado de um processo de mudanças contínuas, causadas pelo animal e que, ao mesmo tempo, afetam o próprio animal.

${ }^{14}$ Cabe esclarecer que esse termo, não pertencente ao léxico da língua inglesa, foi criado pelo próprio Gibson. Ainda que tal termo pudesse vir a ser traduzido, para fins desse contexto, como "concessões", "recursos" ou "possibilidades", optamos, aqui, pela sua manutenção em língua inglesa.
} 
ambiente com o indivíduo. Dessa forma, perceber é descobrir esse conjunto de múltiplas affordances presentes no ambiente. Cabe dizer que a noção de affordances tampouco implica um conhecimento prévio ou mentalista; na verdade, tais propriedades caracterizam-se como potencialidades dos objetos, a serem descobertas pelo indivíduo em meio ao processo de interação com o seu ambiente.

Segundo a proposta gibsoniana, ao longo de nosso processo de interação com o ambiente, vamos descobrindo, através das nossas ações, diversas affordances possibilitadas por um mesmo objeto, a depender dos objetivos dessas interações. É por isso que, sob tal perspectiva, a percepção não é uma resposta a um estímulo, mas, sim, um ato de extrair informações a respeito das potencialidades funcionais do ambiente. Notemos, dessa forma, que o ambiente é rico o suficiente para prover as affordances de que necessita o animal. Por esse motivo, é dispensada, também, a noção de um processamento baseado em representações prévias, durante o ato de perceber.

Ao partirmos dos preceitos acima destacados, podemos pensar que a percepção da fala implica, também, descobrir a funcionalidade e as affordances necessárias, presentes na cadeia de fala, para que se possam extrair distinções funcionais, capazes de distinguir significado. É justamente nessa linha de raciocínio que Best (1995, p. 178) nos diz que, à luz da perspectiva ecológica direta que guia o seu Perceptual Assimilation Model, "assim como percebemos ferramentas físicas (por exemplo, um martelo), em termos das ações potenciais relacionadas a um objetivo que podemos atingir com estas ferramentas (as affordances), percebemos a fala nativa em termos de affordances linguísticas - objetivos comunicativos que podem ser atingidos com ela". O processo de percepção, em outras palavras, é uma descoberta de affordances. O indivíduo é um ser explorador de seu ambiente, de objetos ecológicos ricos em termos de valor e significado. A propriocepção também pode ter um papel importante nesse sentido, uma vez que, ao explorar e interagir sobre o ambiente, o indivíduo não somente percebe os sons desse ambiente, mas também produz articulações que poderão carregar significado, articulações essas que também serão percebidas pelo próprio aprendiz. Uma vez que a informação a respeito das affordances dos objetos está no próprio objeto, Gibson (1979, p. 127) caracteriza sua proposta como uma hipótese radical, pelo fato de que, ao pressupor que os valores e os significados estão externos ao percebedor, deixa claro que tal percepção se dá de maneira direta, por meio do contato do indivíduo com o ambiente, através de sua relação de complementaridade e interação.

São esses os preceitos de base que inspiram a noção de uma teoria realista direta dos sons da fala, proposta por Fowler (1986), e, consequentemente, por Best (1995). Conforme 
expresso acima, Fowler $(1986,1996)$ argumentará que a informação acústica constituirá o meio (ou, melhor dizendo, o meio principal de uma série de meios) através do qual a unidade gestual é percebida. Sendo o gesto a unidade primitiva, devemos considerar o caráter multimodal da percepção (cf. GOLDSTEIN; FOWLER, 2003). De fato, o gesto articulatório pode ser "recuperado" a partir da informação acústica, mas, além disso, da própria informação visual, que pode complementar a acústica ${ }^{15}$. Essa possibilidade de percepção multimodal vai ao encontro da própria abordagem ecológica de Gibson, que pode ser caracterizada, conforme também já expresso, a partir de uma expressão multimodal de relação do indivíduo com o seu ambiente.

Ao considerarmos a unidade gestual, tida como moeda comum tanto para percepção quanto para produção (cf. GOLDSTEIN; FOWLER, 2003), temos, também em termos formais, uma explicação para o nível sonoro da linguagem. É ao pensarmos em tal unidade, enquanto elemento-base da Fonologia Articulatória, que uma série de questionamentos podem vir à tona, a partir da leitura dos artigos de Fowler $(1986,1996)$ e, sobretudo, de Best (1995) e Best e Tyler (2007). Como primeiro questionamento, considerando-se as possibilidades de assimilação previstas no PAM-L2, poderíamos pensar se estariam os indivíduos armazenando unidades gestuais abstratas na sua mente; se assim fosse, os casos de assimilação da língua alvo a categorias da L1 não seriam advindos de comparações entre o estímulo recém ouvido e o previamente armazenado, de modo que a representação abstrata prévia estaria exercendo efeito sobre os tipos de categorizações a serem realizadas como o novo estímulo de L2? Sendo afirmativa a resposta para esse questionamento, de que forma tal perspectiva de aquisição seria distinta de outra de caráter mais indireto?

Como uma possível resposta a esse questionamento, julgamos pertinente incitar discussões referentes à noção de "aprendizado da percepção" (do inglês, perceptual learning, cf. Gibson e Gibson, 1955): como, sob esta perspectiva, "guardamos" o que percebemos? Como resposta, devemos trazer à discussão os trabalhos de Eleanor Gibson, esposa e principal parceira acadêmica do criador da abordagem ecológica da percepção. Em uma entrevista reportada em Szokolszky (2003), a própria E. Gibson reconhece que toma a teoria de seu esposo e a expande para que abarque a questão da aprendizagem daquilo que é aprendido. E. Gibson (1998, 2003, dentre outros), ao explicar de que forma aprendemos a perceber, deixa claro que tal processo se caracteriza como um processo de "diferenciação", e não um

\footnotetext{
15 Além dos tradicionais argumentos advindos do Efeito McGurk (McGURK; McDONALD, 1976), Goldstein e Fowler (2003), com base no estudo de Fowler, Brown e Mann (2000), argumentam a favor da natureza multimodal do gesto, de modo a afirmarem que os ouvintes obtêm a informação gestual tanto multimodalmente quanto unimodalmente.
} 
"processo criativo". Em outras palavras, com mais experiência do ambiente, conseguimos, cada vez mais, diferenciar propriedades do ambiente que antes eram categorizadas como uma única coisa. Aprender a perceber implica, em outras palavras, criar novas categorias. Entretanto, cabe dizer que, uma vez que estamos lidando com uma teoria real, cuja base é a ação, essas categorias não são concebidas como estaticamente abstratas; pelo contrário, conforme dizem Gibson e Gibson (1955), nessa teoria, a percepção é enriquecida a cada resposta diferente, não através de imagens. A percepção se dá em uma correspondência cada vez maior, não menor, com a estimulação. Assim, não estamos "acumulando" imagens de pautas gestuais, e tampouco fazendo com que as "imagens" já armazenadas afetem outras: aprendemos através da ação dos gestos, e, com o contato que vamos tendo com novos estímulos, temos a tarefa de verificar se as ações a que estamos expostos correspondem a uma nova categoria, ou seja, se apresentam uma nova affordance para a língua em questão. Dessa forma, o aprendizado perceptual "consiste em responder a variáveis da estimulação física até então não atendidas" (GIBSON; GIBSON, op. cit., p. 34).

Em suma, encerramos a primeira etapa deste artigo expressando o que entendemos por "percepção", considerando-se a formação de novas categorias fonológicas, para o PAM-L2. Perceber, nesse sentido, advém do contato cada vez maior com novos estímulos ${ }^{16}$, que exibem diferentes funções no ambiente. Esse contato implica discriminar e distinguir ações, sem a necessidade de comparações com categorias puramente abstratas, estáticas e armazenadas na mente. A propriocepção também pode ter papel fundamental, no que diz respeito a essa questão. Por estarmos nos referindo a ações, vemos o papel importante do indivíduo com o ambiente em que se insere. A formação de novas diferenciações é motivada, justamente, pela interação do indivíduo com o referido ambiente: novas discriminações serão feitas se novas utilidades distintivas para essas discriminações se fizerem necessárias, ou seja, se novas affordances forem encontradas. Essa capacidade exploratória está disponível ao longo de toda a vida: pode servir para o reconhecimento alofônico da própria L1, bem como para a verificação de necessidade de formação de novas categorias em uma L2. Constitui, de fato, uma efetiva capacidade de aprendizagem.

\footnotetext{
${ }^{16}$ É justificada, assim, a afirmação de Bundgaard-Nielsen, Best e Tyler (2011), em um artigo que tem por base a noção de realismo direto e o PAM-L2, de que a ampliação do léxico incide sobre a capacidade do indivíduo de perceber sons.
} 


\section{Questionamentos acerca do emprego da abordagem ecológica no PAM-L2}

Ao termos retratado as premissas básicas das propostas do PAM-L2, a partir das teorias de base que o sustentam, expressamos, no que segue, uma série de questionamentos e desafios que consideramos ainda carecer de ser respondidos pelos pesquisadores que desenvolvem pesquisas à luz dessa proposta. Os referidos questionamentos advêm de nossa experiência com o modelo, ainda que alguns dos desafios expressos aqui tenham já sido explicitados, inclusive, pelos próprios proponentes do PAM e do PAM-L2. Cabe destacar que a seguinte relação de questionamentos e desafios, ainda que acompanhada de nossa visão crítica ao longo de toda a seção, não tem a intenção primeira de sugerir respostas ou soluções imediatas para os pontos levantados; de fato, nossa intenção é, primeiramente, apontar questões que precisam ainda de debate e de estudos futuros a respeito do modelo, tanto no plano de investigações nacional quanto internacional, para servir de pano de fundo para trabalhos futuros. Dessa forma, no que segue, lançamos questionamentos referentes à própria natureza ecológica da proposta.

\section{A abordagem ecológica e os estudos laboratoriais}

Considerando-se a noção "realista direta" da perspectiva que motiva o PAM-L2, o primeiro questionamento a ser feito diz respeito a uma questão metodológica, levando-nos a indagar o quão diretos podem ser considerados estudos laboratoriais que se baseiam nesse modelo. Afinal, testes de percepção que se valem de sons gravados, possibilitando o contato com um estímulo não-advindo de uma interação, cujas tarefas levam os participantes a, simplesmente, clicar em botões para identificar ou discriminar sons (sem um fim comunicativo real), poderiam, efetivamente, ser considerados instâncias de uma abordagem ecológica, de modo a retratarem um ambiente real, percebido diretamente?

O questionamento acima apresentado está longe de ser ingênuo. Primeiramente, é preciso discutir as diversas acepções do termo "percepção direta". Por um lado, poderíamos pensar "percepção direta" como aquela que não é mediada por processos cognitivos de inferência ou testagem de hipóteses, ao contrário de uma perspectiva representacional. Nesse sentido, independentemente do quão laboratorial possam ser nossos estudos, julgamos que seria possível, ainda assim, advogar a favor de uma percepção "direta" para tais testes. A questão digna de discussão concerne à outra acepção do termo "direto", que diz respeito, justamente, a uma noção de percepção de acordo com a qual não deve haver nenhum objeto 
ou instrumento mediador (que, nesse caso, estaria assumindo um caráter extrínseco) entre o indivíduo e o ambiente. Conforme as palavras do próprio Gibson (1979, p. 147), "a percepção direta é o que se tem ao se ver as Cataratas do Niágara, ao invés de uma foto dela". Nesse sentido, havendo o papel desse instrumento, a percepção, pelo menos numa noção gibsoniana, não seria direta, porque este último tipo de percepção seria mediada. Dito isso, o quão mediados seriam nossos estudos laboratoriais? Poderiam, portanto, ser considerados representantes de uma percepção direta?

Mais do que a própria questão laboratorial, poderíamos nos perguntar se, sob a noção gibsoniana, a própria comunicação face-a-face pode ser considerada direta, uma vez que a comunicação implica extrair uma mensagem comunicativa a partir da ação do trato vocal, e esse processo de extração da mensagem pode vir a ser considerado indireto. Em seu artigo de 1986, Fowler traz, justamente, essa discussão à tona, ao se referir à percepção da fala. No referido trabalho, a autora, ao citar as obras de Gibson $(1966,1979)$, menciona que a comunicação linguística, ou qualquer outro tipo de percepção que envolva alguma forma de símbolos, é tratada por Gibson como percebida de uma forma indireta. A acepção de "indireto", conforme discutido pelo autor, não implica a necessidade do que Fowler denomina de "mediação cognitiva" (ou seja, de um aparato simbólico que serviria como interveniente), mas, sim, advém do fato de que a informação provida através do falante, do pintor ou do escritor, por exemplo, tenha sido previamente selecionada, o que configura o caráter "indireto" da obtenção da informação a partir desses meios. Assim, para Gibson, toda a informação entendida culturalmente tampouco poderia ser percebida diretamente.

Posicionando-se a esse respeito, Fowler (1986, p. 24) afirma que não consegue "verificar nenhuma diferença fundamental no modo como a percepção ocorre, embora o quê é percebido seja diferente". A autora argumenta que a própria extração de mensagens é também expressa por uma relação direta entre o enunciado e o que ele significa, visto que seu significado é, também, um aspecto cultural que é compartilhado pelos membros daquele grupo, e, dessa forma, não pode ser considerado como exterior ao ambiente do grupo em questão. Com base em uma série de argumentos, Fowler (id. ibid.) sugere que seja dispensada a distinção entre percepção "direta" e "indireta" nesse âmbito de discussão, visto que "tanto a atividade estruturada do trato vocal quanto a informação linguística [...] são diretamente percebidas (por hipóteses) pela extração de informação invariante a partir do sinal acústico, embora a origem da informação seja, de certa forma, diferente”. Em outras palavras, para a autora, "nada é indiretamente percebido" no que diz respeito à fala. 
Até o presente ponto, acreditamos ter verificado que a questão referente a quão direta é a percepção dos sons não parece ser ingênua, uma vez que depende não somente da caracterização do termo "direto", mas, também, dos diferentes posicionamentos de distintos teóricos sobre o assunto. Conforme já discutimos, se considerarmos o papel de mediadores, poderíamos pensar os testes laboratoriais de percepção em L2/LE como "mediados" e, portanto, passíveis de assumir um caráter mais ou menos direto, a depender da perspectiva de cada autor. Ainda no que concerne a esses experimentos, questionamentos adicionais devem ser feitos, também, sobre a natureza dos estímulos: o quão direta seria a percepção de estímulos acusticamente manipulados? E estímulos elaborados em laboratório, através de sintetizadores de fala? Poderiam os estudos que tomam esse tipo de estímulos para testagem ser alicerçados teoricamente por uma teoria de Realismo Direto, ou, especificamente, por modelos como o de Best (1995) e Best e Tyler (2007)?

Em um sentido gibsoniano, considerando-se o fato de que ambos os tipos de estímulo advêm de uma mediação realizada pelo investigador, a resposta seria, indiscutivelmente, negativa. No que diz respeito a uma concepção menos "dura" de abordagem direta (tais como as seguidas por Fowler e Best), julgamos que a questão não se mostra plenamente resolvida, de modo a incitar debates tanto do ponto de vista psicolinguístico quanto filosófico. Afinal, o quão representativos são tais estímulos artificiais do ambiente que cerca o indivíduo, de modo que venham ainda a dar conta de uma perspectiva ecológica de percepção? E o quão "ecológico" precisa ser um estímulo para que possamos pensar na noção de realismo direto? Como reflexões acerca desses questionamentos, concebemos, nesse sentido, duas noções teóricas: uma noção "ecológica" e uma questão "direta", cuja relação, ainda que diretamente estabelecida por Gibson, precisa ser discutida separadamente nesses modelos. Sob a caracterização individualizada de cada uma dessas noções, estímulos manipulados não poderiam ser considerados "ecológicos". Por sua vez, conseguiria o indivíduo "extrair" a unidade gestual a partir desses estímulos? A resposta para essa questão, muito provavelmente, dependerá da natureza dos estímulos de que estamos tratando. Maiores discussões são necessárias para que possamos indagar se essas digressões às duas noções teóricas possibilitam, ainda, que pensemos a percepção sob a concepção que serve de base para o Perceptual Assimilation Model, ou se, por sua vez, há a necessidade de obediência a uma das noções mais do que a outra.

Também no que diz respeito à natureza dos estímulos, outra questão advém das próprias previsões de assimilação e de formação de categorias fonológicas previstas no PAML2. Além de estabelecer que os sons da língua-alvo podem ser organizados em uma nova 
categoria (ou seja, ter sua affordance percebida) ou assimilados às categorias da L1, o modelo ademais prevê que os sons do novo sistema podem ser assimilados a um som da fala não categorizável ou, ainda, não serem assimilados a algum som da fala. Embora todas essas possibilidades teóricas se mostrem efetivamente coerentes, sobretudo, com uma abordagem que tenha por base uma noção ecológica de percepção de sons, questionamentos devem ser feitos a respeito do modo como podemos testar experimentalmente essas duas últimas previsões. Em outras palavras, considerando-se que testes perceptuais, de laboratório, se mostram coerentes com a perspectiva de base do modelo (o que, conforme expresso acima, já é uma questão polêmica por si mesma), como obter uma metodologia que possibilite essas categorizações? Como exemplo, podemos considerar, para fins de ilustração, um teste de identificação: deveria haver a opção "esse não é um som da fala" ${ }^{17}$, além da opção "nenhuma das opções"? Mais do que isso, uma vez que os estímulos fornecidos aos participantes devem também apresentar um número equilibrado dos padrões apresentados, de modo que todas as opções de resposta venham a ser privilegiadas pelos diferentes tokens a que é exposto o participante, deveríamos ainda incluir sons que, inclusive, não pertenceriam ao domínio da fala? Ainda que as previsões referentes aos padrões de assimilação pareçam lógicas e coerentes ao considerarmos o contato do indivíduo com o ambiente, parece que a referida inclusão de tais estímulos poderia vir a ser considerada estranha, em termos experimentais.

Finalmente, apresentamos, como último desafio, questões referentes ao próprio design de estudos de percepção, tais como o de identificação. Julgamos fundamental considerar que, geralmente, as opções de resposta previstas em testes de identificação são apresentadas a partir de convenções ortográficas, baseadas ou no alfabeto, ou em símbolos fonéticos. A escolha, por parte do aprendiz, implica um conhecimento de associação daquilo que está sendo "percebido" com uma simbologia que representa a categoria em que o som-alvo deveria ser enquadrado. Em outras palavras, tais testes acabam por incluir, em seu design, um conhecimento enciclopédico, de convenção culturalmente estabelecida, que não condiria com o tipo de conhecimento que deveria ser efetivamente testado. Considerando-se que testes como os de identificação, ao investigarem a capacidade dos participantes de categorizar unidades sonoras, verificam o estabelecimento de categorias fonológicas através de um tipo

\footnotetext{
${ }^{17}$ Os dados de Best, McRoberts e Sithole (1988) demonstram que falantes monolíngues do inglês americano percebiam os cliques do Zulu como sons não pertencentes ao domínio da fala. Para tal conclusão, os autores contaram com a aplicação de questionários após a realização dos testes perceptuais. Nesses questionários, os autores solicitavam que os participantes descrevessem as propriedades das sílabas utilizadas por eles para basearem suas respostas de discriminação, bem como descrevessem o quão fácil haviam considerado a tarefa. Acreditamos que questionários abertos após a aplicação do instrumento, como o empregado no referido estudo, constituem uma das poucas maneiras (mas, ainda assim, não plenamente isenta de problemas metodológicos) de se concluir que um determinado som não é considerado como pertencente à fala.
} 
de conhecimento enciclopédico e simbólico que, de acordo com a noção gibsoniana, não diria respeito a um elemento encontrado no ambiente (pelo fato de ser culturalmente estabelecido), o quão apropriada seria tal metodologia para verificar os efeitos de uma percepção ecológica?

Em suma, os questionamentos acima expressos dizem respeito, justamente, ao que consideramos um debate cerne referente ao modelo do PAM-L2: a possibilidade de conciliar uma abordagem ecológica com procedimentos laboratoriais. Conforme toda a discussão aqui expressa, resta, primeiramente, discutir se tal união se faz viável em termos epistemológicos. Caso seja considerada possível, permanece o desafio de como conciliar previsões advindas de uma perspectiva ecológica a testagens e metodologias de caráter laboratorial, que venham, de alguma forma, a verificar tais previsões a respeito da interação "indivíduo" vs. "ambiente".

\section{O papel da transferência grafo-fônico-fonológica}

Ao pensarmos em padrões culturalmente definidos, no sentido gibsoniano, a escrita corresponde a um aspecto percebido indiretamente. Assim, tal aspecto não faria parte de sua teoria de percepção. Entretanto, ao considerarmos o processo de aquisição de L2/LE, não há dúvidas de que os padrões ortográficos da língua-materna podem exercer influência não somente na produção, mas também na percepção, das formas-alvo. Zimmer, Silveira e Alves (2009) denominam esse fenômeno como "transferência grafo-fônico-fonológica", concebendo-o como um processo que age conjuntamente do denominado pelos autores de "transferência fonético-fonológica", que tem, como um de seus cernes, problemas de percepção conforme explicados por modelos como o SLM e o PAM. Os autores apontam que, sobretudo em línguas cujo sistema de língua-materna apresenta uma relação previsível entre letras e sons, dificuldades podem vir a ocorrer na aquisição de sistemas cuja relação não se mostra tão transparente. Dessa forma, em alguns casos, pode até constituir tarefa difícil, para o analista, distinguir o tipo de transferência que se mostra ativa para explicar as produções diferentes do alvo do aprendiz (até porque, conforme explicam Alves e Barreto (2012), ambas podem estar em ação ao mesmo tempo).

Ainda que a influência da forma grafada tenha efeitos sobre a própria percepção de LE/L2, nada é dito, a esse respeito, pelo Perceptual Assimilation Model. A justificativa para essa "suposta ausência" reside, justamente, no fato de que tal tipo de transferência não constituiria objeto de estudo da percepção, de acordo com a concepção de Gibson. De fato, a inclusão do ambiente escrito implicaria uma outra variável que poderia desafiar alguns pontos da noção de contato direto do indivíduo com o ambiente, e, até mesmo, uma noção de 
percepção direta sem a intervenção de um mediador simbólico. Uma possibilidade seria pensar que o PAM-L2 seria aplicável apenas nos casos de aquisição em que o adquirente não tem contato com o código escrito da L2; entretanto, tal possibilidade, ainda que teoricamente viável, mostra-se limitada em termos práticos. Assim, consideramos importante que novos estudos tentem estabelecer semelhanças e diferenças entre esses dois tipos de transferência, de modo que as acepções teóricas de base sejam discutidas, para que seja considerada a possibilidade ou não de se levar em conta o papel da ortografia para a percepção, visto que corresponde a um fator cujos efeitos empíricos são inegáveis.

\section{A concepção ecológica e o debate "Segunda Língua" vs. "Língua Estrangeira"}

Um questionamento fundamental referente à concepção de percepção que embasa o modelo advém de uma consideração teórico-metodológica estabelecida em Best e Tyler (2007), originada a partir da noção ecológica que norteia a proposta do Perceptual Assimilation Model-L2. No referido artigo, os autores são categóricos em distinguir os contextos de Aquisição de Língua Estrangeira (ALE), ou seja, aqueles em que o desenvolvimento se dá em um ambiente em que a língua-alvo não tende a ser falada fora da sala de aula, daqueles de Aquisição de Segunda Língua (AL2), no qual a língua-alvo é falada fora de sala de aula, havendo, inclusive, massiva exposição aos padrões de fala nativa estrangeira. Segundo a caracterização dos autores (op. cit., p. 19), "o contexto de aquisição de Língua Estrangeira constitui um ambiente empobrecido da aquisição de Segunda Língua, e as descobertas referentes à ALE não devem ser misturadas com aquelas referentes à AL2" (id. ibid.). Os autores ainda caracterizam a ALE como "menos do que ideal no que diz respeito à natureza ecológica do aprendizado de línguas: ela geralmente ocorre em um ambiente impregnante de L1 e não se estende muito além da sala de aula”. Em função dessa diferença, de acordo com a caracterização dos autores, pelo fato de a ALE não expressar a noção de ambiente ecológico que reflita a teoria de base que sustenta o modelo, a discussão da proposta do PAM-L2 deve ser restrita aos contextos de segunda língua, ainda que considerem que a aplicação ou não do referido modelo aos casos de língua estrangeira constituam um importante foco de investigações vindouras.

As considerações acima devem exercer forte impacto na adoção ou não desse modelo em investigações que tenham, como participantes, aprendizes em um contexto estrangeiro. Uma vez que, conforme expressam os próprios autores, uma maior discussão se faz necessária acerca da referida problemática, julgamos pertinente, aqui, estabelecer algumas 
considerações, não de caráter exaustivo ou esgotador da questão, mas, sim, como argumentos adicionais que estimulem reflexões futuras. Por um lado, reconhecemos que a argumentação e a cautela de Best e Tyler (2007) se mostram coerentes com a perspectiva ecológica que serve de base para a proposta. De fato, considerando-se que a noção de affordances é obtida do contato do indivíduo com o ambiente (no caso da percepção da fala, da finalidade de configurações gestuais com o sentido que está sendo expresso), é fundamental reconhecer o papel da necessidade de uma comunicação significativa, bem como de uma grande exposição à língua-alvo, que expresse a riqueza do ambiente, conforme advogado por Gibson.

Ainda que, indubitavelmente, esses aspectos sejam fundamentais para uma aquisição plena dos componentes da língua-alvo, e que reconheçamos, em diversos casos, o caráter menos rico apontado pelos autores ao se referirem ao input de língua estrangeira, acreditamos que as considerações dizem muito mais respeito à noção de aprendizagem perceptual do que às previsões referentes aos tipos de assimilações L1-L2 propostas pelo PAM-L2. Dessa forma, ainda que, realmente, a noção de aprendizado perceptual talvez precise ser diferenciada entre "Segunda Língua" e "Língua Estrangeira", conforme sugerem os autores, julgamos que não há mecanismos formais ou necessidade de previsões diferenciadas para os ambientes de AL2 ou ALE. Nesse sentido, considerando-se as diferenças apontadas pelos autores, seria possível que os aprendizes de LE mantivessem seus sistemas linguísticos em desenvolvimento em estágios que exibissem um número substancialmente maior de assimilações, conforme as possibilidades previstas pelo modelo, e que, talvez, esse estágio desenvolvimental de ocorrência massiva de assimilações entre os sons de língua-alvo e língua-materna apresentem um caráter mais duradouro ou permanente, no caso desses aprendizes. Isso, obviamente, dependerá da realidade de cada aprendiz e de diversos fatores concernentes ao indivíduo e ao ambiente de ensino-aprendizagem em que ele se encontra. De qualquer forma, em termos de previsão de assimilação, a distinção AL2-ALE não contrariaria as previsões do PAM-L2, mas, sim, poderia servir como fator comprovador das previsões de assimilação (desde que, conforme já dito, seja possível encontrar um equilíbrio entre a teoria de base e a metodologia laboratorial que estabelece tais previsões, desafio esse que independe de o contexto ser de AL2 ou ALE).

\section{Sobre a aplicação do PAM-L2 em estudos de treinamento perceptual}

Ainda como um fator diferenciador entre os contextos de AL2 e ALE, Best e Tyler (id. ibid.) afirmam que "diferentemente de aprendizes de L2 e monolíngues, os aprendizes em um 
contexto de ALE têm exposição à língua-alvo, sobretudo, através de instrução formal em um contexto restrito, com pouca, não-sistemática, experiência conversacional com falantes nativos". Ao considerarmos esse argumento, em princípio poderíamos pensar que estudos de treinamento perceptual em um contexto de LE, de caráter laboratorial, com ampla repetição massiva de tokens produzidos por falantes nativos previamente selecionados, poderiam constituir uma solução para o aperfeiçoamento da capacidade perceptual desses aprendizes, de modo que tais estudos laboratoriais pudessem ser sustentados a partir do PAM-L2. Entretanto, tal possibilidade é, de igual modo, negada por Best e Tyler (2007) ao argumentarem que, ainda que os estudos sobre treinamento constituam, também, uma interessante questão de pesquisa, o modelo tampouco se volta para tais experimentos. O interesse dos autores (op. cit., p. 18), ao propor o PAM-L2, reside em "situações comunicativas naturais, que mais amplamente associam a estrutura gramatical e fonológica da L2", por se basearem em conversações significativas para que se estabeleça o contexto de aprendizado.

No que diz respeito às dúvidas, colocadas por Best e Tyler (2007), acerca da pertinência de concebermos o ambiente de treinamento perceptual como igualmente válido ao efetivo contexto de aquisição de segunda língua, concordamos com os autores que o debate acerca da questão deve ser intensificado. Se, por um lado, ambientes de treinamento podem fornecer oportunidades de exposição ao input massivo e bem direcionados ao aspecto linguístico que desejamos aperfeiçoar, por outro, conforme bem apontam os autores, não necessariamente há um ambiente de busca pela comunicação significativa e pelos sentidos - a busca por affordances, nesse sentido, não é guiada por uma motivação puramente comunicacional. Ainda assim, cremos que os debates acerca da questão devem levar em consideração um aspecto importante. Pensamos que o fato de que não venha a haver uma motivação comunicacional não implica que não haja uma motivação de satisfação de uma tarefa. Indiscutivelmente, atividades de treinamento perceptual são tarefas cujo sucesso (através do provimento de feedback) constituem um objetivo genuíno aos aprendizes. Dessa forma, não se pode negar que há, também, uma busca por affordances, ainda que tal busca não seja guiada pelo objetivo comunicacional em si, mas, sim, pelo interesse no grau de acuidade do próprio exercício. Esse interesse, inegavelmente, dependerá do grau de motivação do aprendiz. Discussões que levem em consideração tal fato são pertinentes, para que seja possível levar adiante o debate referente à noção de aprendizado perceptual de Best $\mathrm{e}$ Tyler (2007) a esses contextos. De qualquer modo, independentemente das conclusões a serem atingidas, julgamos que pelo menos as previsões de assimilação feitas pelo modelo podem, também, ser mantidas. 
Sugerimos um outro aspecto a ser considerado sobre o treinamento perceptual e que diz respeito a uma suposta "vantagem", para o estabelecimento do processo de aquisição (considerado, à luz dos preceitos de Best e Tyler, de formação de categorias fonológicas da L2). Tal aspecto relaciona-se ao fato de, em um contexto de treinamento, o aprendiz estar exposto a uma massiva quantidade de input cuja detecção dos diversos aspectos articulatórios de ordem maior (higher level) constitui condição fundamental para o bom cumprimento do objetivo da atividade proposta. Em meio a um efetivo ambiente de comunicação, o estabelecimento do significado, pré-requisito da comunicação, pode ocorrer, inclusive, sem a plena detecção desses aspectos distintivos ${ }^{18}$, uma vez que o input é rico em diversas informações que podem compensar a não-detecção de articulações distintivas em algumas interações específicas. Seguindo-se essa linha de raciocínio, a detecção das invariantes articulatórias talvez ocorra somente naqueles contextos em que a não-detecção de tais aspectos possa ter influências substanciais na comunicação (o que, considerando-se um ambiente em que há contextualização, constitui casos menos frequentes), ou nos casos em que realmente o aprendiz seja motivado a atentar aos detalhes da forma. Por sua vez, os estímulos de treinamento perceptual tendem a ser descontextualizados (o que aumenta a necessidade de atentar para os aspectos invariantes, para o bom cumprimento da atividade), apresentados em uma grande quantidade de tokens e elaborados de forma tal que a sua não detecção não possa ser compensada por outro aspecto, para a boa execução da tarefa ${ }^{19}$. Dessa forma, ainda que tal ambiente experimental não constitua uma noção ecológica, e tampouco seja considerada como de percepção direta por Gibson, estudos futuros devem concentrar-se em verificar de que maneira tais contextos podem ou não estar em consonância com as previsões de formação de categorias fonológicas de Best e Tyler (2007). Acreditamos que maiores considerações acerca dessa questão passam, necessariamente, por uma melhor caracterização do que significa a noção de "atenção" à luz do PAM-L2.

\footnotetext{
${ }^{18}$ Essa possibilidade é, inclusive, reconhecida no artigo de Best e Tyler (2007). Para uma maior discussão a esse respeito, e à necessidade de atenção ao input, sugerimos a leitura de Zimmer, Silveira e Alves (2009).

${ }^{19}$ Grande parte das tarefas de treinamento perceptual são baseadas em testes de identificação que, conforme já apontado anteriormente, recorrem a um conhecimento enciclopédico, baseado no sistema alfabético, para o cumprimento da atividade. Ao recordarmos esse fato, questionamos, novamente, se tal ambiente remontaria a uma perspectiva ecológica de aprendizado da percepção. Discussões a esse respeito podem ser desenvolvidas a partir de dois eixos: (a) questionando-se se as previsões de assimilação e aprendizado perceptual do PAM-L2 não poderiam ser considerados pertinentes, também, em contextos "menos ecológicos"; (b) indagando-se sobre o quão realista direta é a resolução não somente de tarefas de percepção, mas, também, do próprio processo de aprendizado perceptual advogado em Best e Tyler (2007).
} 


\section{"Percepção" e "inteligibilidade": uma conjunção necessária em uma perspectiva ecológica}

Finalmente, ainda ao nos referirmos à concepção de aprendizado guiado pela comunicação significativa, característica de uma perspectiva ecológica e defendida explicitamente em Best e Tyler (2007), resta dizer que, em meio a um ambiente considerado ecológico, a percepção de sons constitui um aspecto componente de um construto ainda maior - a inteligibilidade. Falar em comunicação efetiva e estabelecimento de significado implica, em outras palavras, referir-nos a uma fala inteligível, apesar do fato inegável de que há muitas definições diferenciadas para tal construto ${ }^{20}$. Independentemente da definição a ser adotada, julgamos fundamental considerar os seguintes fatos: (a) a percepção individual dos sons contribui para o estabelecimento da inteligibilidade ${ }^{21}$; (b) apesar do fato expresso em (a), a inteligibilidade constitui um construto maior do que a percepção individual dos sons; assim, ainda que a percepção possa, por muitas vezes, compreender condição fundamental para a fala inteligível, outros aspectos exercem importante papel no processo, de modo que a inteligibilidade seja atingida sem necessariamente a obtenção de índices plenos (100\%) de percepção de sons individuais.

Dito isso, dado que o objetivo central da comunicação é a fala inteligível, concluímos que, em meio ao processo de comunicação, a busca de affordances não se restringe apenas à unidade gestual, mas que tal busca inclui uma série de fatores, tanto linguísticos quanto os caracterizados como extra-linguísticos ${ }^{22}$. Dificuldades na percepção podem ser compensadas, em certas instâncias, nas descobertas de affordances desses outros fatores. Assim sendo, considerando-se o pano de fundo "ecológico" que sustenta o PAM-L2 e as noções de Best e Tyler (2007), cremos que desafios conceptuais futuros interessantes implicarão reflexões teóricas que conjuguem as noções de percepção e inteligibilidade, de modo que, ao mesmo tempo em que se esclareçam as diferenças entre esses dois entes teóricos, seja definida a relação intrínseca entre esses dois construtos, em meio à interação do indivíduo com o ambiente. Acreditamos que essa associação se faz necessária, inegavelmente, a partir de uma abordagem ecológica.

\footnotetext{
${ }^{20}$ Para uma discussão a respeito das diferentes caracterizações do termo "inteligibilidade", veja-se Becker (2013) e Derwing e Munro (2015).

${ }^{21}$ Schwartzhaupt (2015) propõe uma caracterização do construto de "inteligibilidade" em LE que compreenda, como parte integrante, a percepção dos sons da LE. Sob a visão do autor, a noção de inteligibilidade depende, inegavelmente, da percepção, mas também é estabelecida através de outros fatores, tais como o contexto da conversação, o ambiente da fala e diferenças individuais dos membros da comunicação.

${ }^{22}$ Cabe esclarecer que, neste momento, estamos nos referindo à noção de percepção direta de Fowler (1986, 1996), em oposição à de Gibson $(1966,1979)$, conforme as diferenças já expressas anteriormente.
} 
Assim, ao termos discutido as implicações de uma concepção estritamente ecológica para uma perspectiva de aquisição como aquela expressa em Best e Tyler (2007), devemos finalizar expondo nosso posicionamento de que, mais do que um debate instaurado a partir de uma visão dicotômica entre ASL x ALE, a pertinência do modelo deve ser vista de uma maneira mais individualizada, centrada no indivíduo. Julgamos que deve ser considerada a própria noção de aquisição de linguagem enquanto desenvolvimento de um sistema adaptativo complexo, que constitui um dos eixos basilares da própria noção do PAM-L2 e que, nos últimos anos, tem recebido grande destaque ao ser defendida por uma série de estudiosos que conjugam estudos psicolinguísticos e aplicados (LARSEN-FREEMAN; CAMERON, 2008; BECKNER et al., 2009; ELLIS, 2011; ELLIS; LARSEN-FREEMAN, 2014). Dessa forma, devemos expressar nossa conclusão de que, mais do que uma visão dicotômica, os indivíduos participantes do processo, bem como o ambiente em que se encontram inseridos, devem ser tomados individualmente em suas realidades e contextos de aprendizagem.

\section{Conclusão}

Ao reconhecermos a grande difusão do PAM-L2 (BEST; TYLER, 2007) entre os pesquisadores de aquisição fonético-fonológica de LE/L2, neste trabalho, tivemos a intenção de discutir as teorias de base que sustentam a referida proposta. Após uma exposição dos princípios gerais que servem de sustentação teórica e epistemológica para o modelo, apresentamos uma série de questionamentos e pontos que incitam pesquisas futuras. Tais desafios advêm, a nosso ver, da grande empreitada de conciliar uma teoria ecológica, ambientalista, com procedimentos de laboratório que possibilitem validação das previsões de tal proposta. Consideramos essa empreitada como uma problematização teórica a ser considerada conjuntamente, através da união de força de linguistas, psicólogos cognitivistas e filósofos.

Concluímos que grande parte dos questionamentos referentes ao modelo advém da necessidade de se estabelecer uma metodologia experimental que, ao mesmo tempo, seja capaz de testar as previsões de assimilação e se mostre coerente com a perspectiva ecológica, realista e direta que guia a proposta de Best e seus colegas. A apresentação dessas questões, conforme já expresso, não teve caráter exaustivo, tampouco de busca de soluções imediatas para o que consideramos uma extensiva problemática; tivemos, sim, a intenção de incitar futuras discussões e investigações que propiciem o desenvolvimento do modelo. Futuros questionamentos teóricos devem dizer respeito à adoção do primitivo gestual para o 
Perceptual Assimilation Model, de modo que questionemos acerca de como tal primitivo pode ser "adquirido", quais os limites de suas bordas, bem como a maneira a partir da qual tal primitivo pode ser pensado, considerando-se os níveis "fonético" e "fonológico" expressos no artigo de 2007.

Esperamos que a discussão aqui apresentada contribua para um entendimento maior, por parte dos pesquisadores da área, acerca das concepções de base que sustentam o modelo, bem como incentivem novas propostas, discussões e pesquisas, de modo a contribuir com o desenvolvimento do PAM-L2.

ALVES, Ubiratã Kickhöfel; SILVA, Adelaide Hercília Pescatori. Implications of a Direct Realist view for PAM-L2: Theoretical and methodological challenges. Revista do GEL, v. 13, n. 1, p. 107-131, 2016.

Abstract: In this article, we discuss the theoretical tenets of the direct realist and ecological approach that guide the Perceptual Assimilation Model-L2 (PAM-L2), (BEST, TYLER, 2007), aiming to highlight the core assumptions and the theoretical and methodological challenges deriving from this model. We address the following aspects: (i) the harmony between the theoretical basis employed in PAM-L2 and the performance of laboratory studies; (ii) the explanatory power of the model when dealing with the process of grapho-phonicphonological transfer; (iii) the ecological approach and the debate between 'Second' and 'Foreign' Language Acquisition; (iv) the use or not of the model in perceptual training studies; (v) the ecological approach and the discussions on 'speech perception'- and 'intelligibility'. We believe that the present discussion may raise awareness among L2 researchers about the core theoretical bases which guide this perceptual model.

Keywords: Speech perception; SL/FL Acquisition; Ecological Approach to Perception; Direct Realism.

\section{Referências}

ALBUQUERQUE, J. I. A. Aspectos da percepção da dessonorização terminal do inglês por falantes nativos do português brasileiro. 2012. $213 \mathrm{f}$. Dissertação (Mestrado em Letras) - Programa de Pós-Graduação em Letras, Universidade Federal do Paraná, Curitiba, 2012.

ALVES, U. K.; BARRETO, F. M. O processamento e a produção dos aspectos fonéticofonológicos da L2. In: LAMPRECHT, R. R.; BLANCO-DUTRA, A. P.; SCHERER, A. P. R.; BARRETO, F. M.; BRISOLARA, F. B.; SANTOS, R. M.; ALVES, U. K. Consciência dos sons da língua: subsídios teóricos e práticos para alfabetizadores, fonoaudiólogos e professores de língua inglesa. 2. ed. rev. Porto Alegre: EDIPUCRS, 2012. p. 193-209. 
BECKER, M. R. Inteligibilidade da língua inglesa sob o paradigma de Língua Franca: percepção de discursos de diferentes L1s por brasileiros. 2013. 260 f. Tese (Doutorado em Letras) - Programa de Pós-Graduação em Letras, Universidade Federal do Paraná, Curitiba, 2013.

BECKNER, C.; ELLIS, N. C.; BLYTHE, R.; HOLLAND, J.; BYBEE, J.; KE, J.; CHRISTIANSEN, M. H.; LARSEN-FREEMAN, D.; CROFT, W.; SCHOENEMANN, T. Language is a Complex Adaptive System - Position Paper. Language Learning, v. 59, supl. 1, p. 1-26, 2009.

BEST, C. T. The emergence of native-like phonological influences in infants: A perceptual assimilation model. In: GOODMAN, J.; NUSBAUM, H. C. The Development of Speech Perception: the transition from speech sounds to spoken words. MIT Press, 1994a. p. 167224

Learning to perceive the sound pattern of English. In: ROVEE-COLLIER, C.; LIPSITT, L. Advances in Infancy Research. Ablex, 1994b. p. 217-304.

A direct realist view of cross-language speech perception. In: STRANGE, W. Speech perception and linguistic experience: issues in cross-language research. Timonuim, MD: York Press, 1995. p. 171-204.

BEST, C. T.; McROBERTS, G. W.; SITHOLE, N. M. Examination of perceptual reorganization for nonnative speech contrasts: Zulu click discrimination by English-speaking adults and infants. Journal of Experimental Psychology: human perception and performance, v. 14, n. 3, p. 345-360, 1988.

BEST, C. T.; TYLER, M. D. Nonnative and second-language speech perception: commonalities and complementarities. In: BOHN, O. S.; MUNRO, M. J. Language Experience in Second Language Speech Learning: In honor of James Emil Flege. Amsterdam/Philadelphia: John Benjamins Publishing Company, 2007. p. 13-34.

BETTONI-TECHIO, M. Perceptual Training and word-initial /s/-clusters in Brazilian Portuguese/English Interphonology. 2008. $201 \mathrm{f}$. Tese (Doutorado em Letras) - Programa de Pós-Graduação em Letras, Universidade Federal de Santa Catarina, Florianópolis, 2008.

BOERSMA, P; WEENINK, D. Praat - Doing Phonetics by Computer. Disponível em: www.praat.org. 2015.

BROWMAN, C.; GOLDSTEIN, L. Towards an Articulatory Phonology. Phonology Yearbook, 3, p. 219-252, 1986.

Articulatory Phonology: an overview. Phonetica, 49, p. 155-180, 1992.

BUNDGAARD-NIELSEN, R. L.; BEST, C. T.; TYLER, M. D. Vocabulary size is associated with second-language vowel perception performance in adult learners. Studies in Second Language Acquisition, v. 33, p. 433-461, 2011.

DERWING, T.; MUNRO, M. The interface of teaching and research: what type of pronunciation instruction should L2 learners expect? In: LUCHINI, P. L.; GARCÍA 
JURADO, M. A.; ALVES, U. K. Fonética y Fonología: articulación entre enseñanza e investigación. Mar del Plata: Universidad Nacional de Mar del Plata, 2015.

DIEHL, R. L.; LOTTO, A. J.; HOLT, L. L. Speech Perception. Annual Review of Psychology, v. 55, p. 149-179, 2004.

ELLIS, N. The emergence of language as a complex adaptive system. In: SIMPSON, J. (Org.). The Routledge Handbook of Applied Linguistics. London: Routledge/Taylor Francis, 2011. p. 666-679.

ELLIS, N.; LARSEN-FREEMAN, D. Language Emergence: Implications for Applied Linguistics. Applied Linguistics, v. 27, n. 4, p. 558-589, 2014.

ESCUDERO, P.; BOERSMA, P. The subset problem in L2 perceptual development: multiple-category assimilation by Dutch learners of Spanish. In: SKARABELA, B.; FISCH, S.; DO, A. (Eds.). Proceedings of the 26th Annual Boston University Conference on Language Development, Cascadilla, 2002. p. 208-219.

FLEGE, J. E. Second Language Speech Learning: Theory, findings, and problems. In: STRANGE, W. (Ed.). Speech perception and linguistic experience: Issues in crosslanguage research. Timonium, MD: York Press, 1995. p. 233-277.

Assessing constraints on second-language segmental production and perception. In MEYER, A.; SCHILLER, N. (Ed.). Phonetics and phonology in language comprehension and production: differences and similarities. Berlin: Mouton, 2003.

FOWLER, C. An event approach to the study of speech perception from a direct-realist perspective. Journal of Phonetics, v. 14, p. 3-28, 1986.

Listeners do hear sounds, not tongues. The Journal of the Acoustical Society of America, v. 99, n. 3, p. 1730-1741, 1996.

FOWLER, C.; BROWN, J.; MANN, V. Contrast effects do not underlie effects of preceding liquid consonants on stop identification in humans. Journal of Experimental Psychology: Human Perception and performance, v. 26, p. 877-888, 2000.

GIBSON, J. J. The senses considered as perceptual systems. Boston: Houghton Miffin, 1966.

The ecological approach to visual perception. Psychology Press, 1979.

GIBSON, J. J.; GIBSON, E. J. Perceptual learning: differentiation or enrichment? Psychological Review, v. 62, n. 1, p. 32-41, 1955.

GIBSON, E. Exploratory behavior in the development of perceiving, acting, and the acquiring of knowledge. Annual Review of Psychology, v. 39, p. 1-42, 1988.

The world is so full of a number of things: on specification and perceptual learning.

Ecological Psychology, v. 15, n. 4, p. 283-287, 2003. 
GOLDSTEIN, L.; FOWLER, C. A. Articulatory Phonology: A Phonology for Public Language Use. In: SCHILLER, N. O.; MEYER, A. E. (Ed.). Phonetics and Phonology in Language Comprehension and Production. Mouton de Gruyter, 2003. p. 159-207.

GORDON, I. E. Theories of visual perception. Hove: Psychology Press, 2004.

LARSEN-FREEMAN, D.; CAMERON, L. Complex Systems and Applied Linguistics. Oxford University Press, 2008.

LIBERMAN, A. M.; COOPER, F. S.; SHANKWEILER, D. P.; STUDDERT-KENNEDY, M. Perception of the speech code. Psychological Review, 74, p. 431-461, 1967.

LIBERMAN, A. M.; COOPER, F. S.; SHANKWEILER, D. P.; STUDDERT-KENNEDY, M.; MATTINGLY, I. G. The motor theory of speech perception revised. Cognition, v. 21, p. $1-36,1985$.

MACHRY DA SILVA, S. Aprendizagem fonológica e alofônica em L2: Percepção e produção das vogais médias do português por falantes nativos do espanhol. 2014. 257 f. Tese (Doutorado em Letras) - Pontifícia Universidade Católica do Rio Grande do Sul, Porto Alegre, 2014.

McGURK, H.; MacDONALD, J. Hearing lips and seeing voices. Nature, v. 264, p. 746-748, 1976.

MUNRO, M. J.; BOHN, O. The study of second language speech learning: A brief overview. In: BOHN, O. S.; MUNRO, N. J. (Ed). Language experience in Second language Speech Learning. Amsterdam: John Benjamins, 2007, p. 3-12.

NISHIDA, G. Sobre teorias de percepção de fala. 2012. 226 f. Tese (Doutorado em Letras) - Programa de Pós-Graduação em Letras, Universidade Federal do Paraná, Curitiba, 2012.

As bases acústica e articulatória das teorias de percepção da fala. Revista do GEL, v. 11, n. 1, p. 142-167, 2014a.

Primitivos de análise na percepção da fala. In: BRAWERMAN-ALBINI, A.; GOMES, M. L. de C. (Org.). O jeitinho brasileiro de falar inglês: Pesquisas sobre a pronúncia do inglês por falantes brasileiros. São Paulo: Pontes, 2014b. p. 49-63.

PEROZZO, R. V. Percepção de oclusivas não vozeadas sem soltura audível em codas finais do inglês (L2) por brasileiros: o papel da instrução explícita e do contexto fonéticofonológico. 2013. 193 f. Dissertação (Mestrado em Letras) - Programa de Pós-Graduação em Letras, Universidade Federal do Rio Grande do Sul, Porto Alegre, 2013.

RAUBER, A. S.; RATO, A.; KLUGE, D. C.; FIGUEIREDO, M. TP - Testes de Percepção / Tarefas de Treinamento Perceptual. Disponível em: www.worken.com.br. 2015.

REIS, M. Percepção de sons de língua estrangeira pelo Modelo de Assimilação Perceptual. Domínios de Lingu@gem, v. 5, n. 1, p. 85-109, 2011. 
SANTOS, G. R. dos. Percepção e produção das vogais médias do espanhol por falantes do português brasileiro. 2014. 170 f. Tese (Doutorado em Letras) - Programa de PósGraduação em Letras, Universidade Católica de Pelotas, Pelotas, 2014.

SCHWARTZHAUPT, B. M. Testing intelligibility in English: the effects of Positive VOT and contextual information in a sentence-transcription task. 2015. $86 \mathrm{f}$. Dissertação (Mestrado em Letras) - Programa de Pós-Graduação em Letras. Universidade Federal do Rio Grande do Sul, Porto Alegre, 2015.

STRANGE, W. Automatic Selective Perception (ASP) of first and second language speech: a working model. Journal of Phonetics, v. 29, p. 456-466, 2011.

SZOKOLSZKY, A. An interview with Eleanor Gibson. Ecological Psychology, v. 15, n. 4, p. 271-281, 2003.

TATHAM, M.; MORTON, K. A Guide to Speech Production and Perception. Edinburgh University Press, 2011.

ZIMMER, M. C.; SILVEIRA, R.; ALVES, U. K. Pronunciation Instruction for Brazilians: Bringing Theory and Practice Together. Cambridge Scholars Publishing, 2009.

Submetido em 20/10/2015

Aceito em 29/03/2016 